\title{
Yaylalardaki Arazi Kullanım Değişiminin Coğrafi Bilgi Sistemi İle Analizi: Giresun Örneği
}

\author{
Volkan BAŞER* \\ Giresun Üniversitesi, Mühendislik Fakültesi, Harita Mühendisliği Bölümü, Giresun
}

\begin{abstract}
$\ddot{O} z$
Türkiye'de yaylalar uzun yıllar hayvancılık ve yazlık dinlenme alanları olarak kullanılmıştır. Günümüzde ise büyük ölçüde nitelik değiştirerek rekreasyon amacıyla kullanılan birer tatil ya da dinlenme yeri olmuşlardır. Bu mekanlara artan talep arazi kullanımında değişime neden olmaya başlamıştır. Turizm anlayışındaki değişime paralel olarak, iç turizmde rekreasyon/turizm için yaylalara olan talep artı̧ıı, Doğu Karadeniz Bölgesi'ndeki bazı yaylaları turizm merkezlerine dönüștürmüş ve buralara yapılan turizm yatırımlarını arttırmıştır. Bu değişim süreci ile birlikte yaylalardaki arazi kullanımı, çevrenin görünümünde ve ekosistemlerde büyük değişikliklere yol açmıştır. Artan bu talep kaçak yapılaşmaları arttırmıştır. İmar afları ile kaçak yapıların hukuki sorunlarının kaldırılması arazi yönetimi kapsamında sıkıntıları beraberinde getirmiştir. Sürdürülebilir olmaktan çıkan yayla alanları her geçen gün doğal kaynaklarını kaybetmektedir. Çalışma Türkiye'nin Doğu Karadeniz Bölgesindeki Giresun ili (Kümbet, Bektaş ve Çıkrıkkapı) yaylalarındaki arazi kullanımında meydana gelen artışı incelemektedir. Bu maksatla 1970-2018 yılları arasında yaylalara ait hava fotoğrafları ve haritalar Coğrafi Bilgi Sistemi (CBS) ile analiz edilmiştir. Yapılan çalışma ile arazi kullanımı ve planlamasına ilişkin sorunlar ortaya konmuş, değişimin boyutlarını irdelenmiştir. Bu bağlamda yaylaların merkezi kullanım alanlarında büyük artışların olduğu, yayla evlerinin betonarme ve çok katlı hale dönüştüğü belirlenmiştir. Buna bağlı olarak yayla yollarında büyük artışlar olmuş ve dağ ekosisteminde bozulmalar meydana gelmiştir. Ayrıca yaylaların kayıt altına alınması ve yapılaşmaların yayla imar planları dâhilinde gerçekleştirilmesi gereğine vurgular yapılmıştır.
\end{abstract}

Anahtar kelimeler: Arazi Yönetimi, Arazi Kullanımı, Hava Fotoğrafi, CBS, Yayla, Giresun.

\section{Analysis of Land Use Change of Highlands with Geographic Information System: The Case of Giresun}

\begin{abstract}
Highlands in Turkey has been used for many years as livestock and summer recreation areas. Today, they have become a vacation or resting place, which is used for recreational purposes by largely changing the quality. Increasing demand for these spaces has begun to cause change in land use. Parallel to the change in tourism understanding, the increase in demand for recreation / tourism in domestic tourism has transformed some of the springs in the Eastern Black Sea Region into tourism centers and increased tourism investments made in the region. Along with this change process, the use of land in the past has led to major changes in the landscape and ecosystems. This increased demand has increased illegal construction. The removal of the legal problems of the illegal structures with zoning amnesty has brought difficulties in the scope of land management. Highland areas that are becoming sustainable lose their natural resources day by day. Working in Turkey's eastern Black Sea region of Giresun province (Kumbet, Bektas and Çikrikkapi) in land use springs examines the changes occurring. For this purpose, aerial photographs and maps belonging to the spring of 1970-2018 were analyzed with the Geographic Information System (GIS). In this study, problems related to land use and planning were determined and the dimensions of change were examined. In this context, it is determined that there are big increases in the central usage areas of the plateaus and the highland houses have become concrete and multi-storey. Due to this, there have been large increases in highland roads and disturbances in the mountain ecosystem. Furthermore, it was emphasized that the plateaus should be recorded and the developments should be carried out within the scope of the land development plans.
\end{abstract}

Keywords: Land Management, Land Use, Aerial Photography, GIS, Highland, Giresun.

"Sorumlu yazar: volkan.baser@giresun.edu.tr

Geliş Tarihi: 20.07.2018, Kabul Tarihi: 27.12.2018 


\section{Giriş}

Araziden yararlanma ya da arazi kullanımı yerleşim alanı oluşturma, ulaşım için yararlanma, ticaret, endüstri ve tatil zamanlarını değerlendirme ve hammadde kazanma da dâhil olmak üzere araziden her türlü yararlanmayı içermektedir [1]. Arazi kullanımı çevrenin görünümünde ve ekosistemlerde daha önce görülmemiş değişikliklere yol açmaktadır. Kentsel alanlar ve buna bağl1 altyapılar en hızlı büyüyen arazi tüketicileridir. Arazi kullanımı kırsal peyzajlar, tarımın yoğunlaşması, arazi terki ve ormanların sömürülmesine bağlı olarak değişmektedir.

Kıyı kesimleri ve dağlık bölgeler, yoğun turizm ve tatil faaliyetlerini karşılayabilmek için mekânsal yeniden düzenlemelere tabi tutulmaktadır. Tarım, ormancılık, ulaşım ve barınma gibi faaliyetler için arazi kullanılmakta ve bu faaliyetlere bağlı olarak toprağın doğal durumu ve işlevi değişmektedir. Arazi kullanımı kaynaklı çevre sorunları; iklim değişikliğine, biyolojik çeşitliliğin kaybına, suyun, toprağın ve havanın kirlenmesine yol açmaktadır. Arazi kullanımından kaynaklanan etkiler, doğal habitatların ve peyzajların yok olması şeklinde doğrudan olabileceği gibi, toprağın sertleşmesi ve ormansızlaşma sonucunda sel riskinin artması ile dolaylı da olabilir [2]. Bu bağlamda, özellikle son yüzyılda dünya nüfusundaki olağanüstü artış ve bu artışa bağlı olarak doğal kaynakların aşırı derecede kullanılması, onarılması güç zararları ve felaketleri beraberinde getirmiştir.

Arazi yönetimi çalışmalarında arazi kullanım türleri belirlenirken veri toplanması, verilerin analizi ve haritalanmasında uzaktan algılama ve coğrafi bilgi sistemleri (CBS), hava fotoğrafları gibi araç ve tekniklerden yararlanılmaktadır.

Arazi örtüsü (land cover), arazi kullanımı (land use) ve arazinin işlevi (land function) kavramları birbiriyle ilişkili ancak farklı anlamlar ihtiva ederler. Arazi örtüsü, arazinin yüzeyindeki bitki örtüsünü içeren toprak tabakasını, tarım ürünlerini ve insan yapılarını ifade eder. Arazi örtüsü bu yüzden doğrudan arazide ve uzaktan algılama görüntüleri ile gözlenebilir. Arazi örtüsü ile ilgili gözlem ve izleme çalışmalarında kullanılan temel araç ve teknikler: Uzaktan algılama, hava fotoğrafları ve haritalardır. Arazi kullanımı ile ilgili çalışmalarda kullanılan temel araç, teknik ve veriler ise; nüfus verileri, gözlemlerden elde edilen arazi örtüsü haritaları, peyzaj yapılarının yorumlarıdır [3].

Arazinin işlevi, yalnızca arazi kullanımını ifade eden mal ve hizmetlerin sağlanması değil, aynı zamanda estetik güzellik, kültürel miras ve bioçeşitliliğin korunması gibi yararların sağlanmasını da içermektedir. Arazi örtüsü ve kullanımında yararlanılan teknikler bir alanın işlev ya da fonksiyonlarının gözlenmesi ve izlenmesi için yeterli değildir. Çünkü bir alanın işlevi arazi örtüsünde herhangi bir değişiklik olmaksızın keskin bir şekilde değişebilmektedir. Dolayısıyla, arazi işlevinin gözlenmesi ve izlenmesi çalışmalarında kullanılan temel araç ve teknikler ise, diğerlerinden farklı olarak, çevresel ve sosyo-eonomik yapının analizi, mal ve hizmetlerin kıymetlendirilmesi ya da ölçülmesidir [3]. Arazi kullanımı değişiklikleri, insan faaliyetleri ve doğal ekolojik süreçlerden kaynaklanmaktadır [4]. Bu değişikliklerin kapsamlı bir şekilde anlaşılması için, uzun vadeli insan-çevre etkileşimleri analiz edilmelidir [5].

Yukarıda sözü edilen araç ve tekniklerin yaygın şekilde kullanılması sonucu dünyanın farklı bölgelerinde arazi örtüsü ve arazi kullanımında meydana gelen değişimleri saptamak amacıyla çok sayıda araştırma ve bu araştırmaların sonuçlarını içeren yayınlar [6-15] yapılmıştır. Çalışmalar dağlık bölgelerde arazi örtüsü ve arazi kullanımında belirli bir zaman aralığında meydana gelen değişim ve bu değişimin ekolojik, ekonomik ve sosyal etkileri ya da sonuçlarını belirleme üzerinedir.

Ülkemizde yaylalar genellikle ekonomiye katkı sağlama alanları olarak görülmektedir [16]. Dağlık alanlarda yer alan yaylalar, göçebe ve yarı göçebelerle, köylülerin ekonomik faaliyet alanı olup, bu alanlardaki ekonomik faaliyetin temelini hayvancılık oluşturur. Bunun yanında yaylalar, kasaba ve kentlerde yasayan insanların "rekreasyonel" amaçlar için kullandıkları, yüksek kesimlerde bulunan geçici veya dönemlik yerleşim yerleridir [17]. Sınırları içinde Giresun ilini de barındıran Doğu Karadeniz Bölgesi, doğal koşullar bakımından yüksek ve engebeli bir alan olduğundan tarımsal faaliyetler için kullanılabilecek arazi son derece sınırlıdır. Bu nedenle bölgede öteden beri hayvancılık, dolayısıyla yaylacılık önemli bir faaliyet olmuştur.

Özellikle son yıllarda Türkiye'de turizm kalıplarındaki değişime paralel olarak Doğu Karadeniz bölgesi, iç ve dış turizmdeki talep artışının yoğun olduğu bölgelerdendir. Doğu Karadeniz Bölgesi'ndeki bazı yaylalar turizm merkezlerine dönüşmüştür. Ayrıca yabancı turist talebinin yoğun olması nedeniyle bölgede turizm yatırımları planlanmakta ve hayata geçirilmektedir. Bölgede bu süreçle birlikte arazi kullanımında ve yayla işlevlerinde hızlı bir değişim başlamıştır. Bu değişime bağlı olarak hayvancılığa 
dayalı geleneksel yaylacılık gerilemiştir. Bu gerileme ile bölgedeki büyükbaş ve küçükbaş hayvan sayısında azalma ve hayvansal üretimde düşüş meydana gelmiş̧ir. Değişim Giresun ili yaylalarında da kendisini göstermektedir.

Yaylalara erişim için yeni yayla yollarının yapımı ve var olan yolların genişletilmesi plansız bir şekilde artarak devam etmektedir. Yaylalarda çoğunluğu yasal olmayan ikinci konut niteliği taşıyan evlerin inşasında ciddi artışlar olmuştur. Bölgede kitle turizmine yönelik artışlar vardır [18].

$\mathrm{Bu}$ araştırmanın temel amacı Doğu Karadeniz Bölgesi yaylalarında arazi kullanımı ve yayla işlevinde meydana gelen değişimin boyutlarını ve nedenlerini Giresun iline bağlı üç yayla üzerinde irdelemektir. Araştırma alanı olarak seçilen Kümbet, Bektaş ve Çıkrıkkapı yaylalarıdır. Araştırmada (1) yaylaların 1970-2008-2018 yıllarındaki hava fotoğraflarından faydalanarak arazi kullanımında meydana gelen değişiklikleri saptamak; (2) yaylaların günümüzdeki işlevini belirlemek ve yayla işlevinde geçmiş yıllara göre değişiklik varsa bu değişikliği ve nedenlerini ortaya çıkarma amaçlanmıştır.

\section{Mera ve Yaylalarda Hukuki Statï}

Yaylaların ve mera alanlarının hukuki statüsü Tablo 1'de verilmiştir. Bu kronolojik sıra mera alanlarına ilişkin tarihsel akışı oluşturmaktadır.

Tablo 1. Mera Kanunu Tarihçesi

\begin{tabular}{lll}
\hline Tarih & Sayı & Mevzuat \\
\hline 1858 & & Arazi Kanunname-i Hümayumu \\
1924 & 442 & Köy kanunu \\
1930 & 1580 & Belediyeler Kanunu \\
1945 & 4753 & Çitçiyi Topraklandırma Kanunu \\
1956 & 6831 & Orman Kanunu \\
1973 & 1757 & Toprak ve Tarım Reformu Kanunu \\
1982 & & T.C. Anayasa \\
1983 & 2924 & Orman Köylülerinin Kalkınmalarının Desteklenmesi Hakkında Kanun \\
1984 & 3083 & Sulama Alanlarının Düzenlemesine Dair Tarım Reformu Kanunu \\
1985 & 3194 & İmar Kanunu \\
1985 & 3202 & Köy Hizmetleri Genel Müdürlüğü Kuruluş ve Görevleri Hakkında Kanun \\
1985 & 3155 & Tarım Reformu Genel Müdürlüğü Kuruluş ve Görevi Hakkında Kanun \\
1987 & 3402 & Kadastro Kanunu \\
1998 & 4342 & Mera Kanunu \\
\hline
\end{tabular}

Bu düzenlemelerle meraların, su ve çim kaynaklarının ancak arazide ortak mülkiyet statüsüne sahip köy veya köy halkları tarafindan kullanılabileceği vurgulanmıştır. Bu arazilerin alım satımı yapılamayacağı belirtilmiştir [19]. 1998 yılında yürürlüğe giren 4342 Sayılı Mer'a Kanunu, sadece merayı kapsamayıp; yaylak, kışlak ve kamuya ait otlak ve çayırların tespit, tahdit ile köy veya belediye tüzel kişilikleri adına tahsis yapılmasını, bakım ve ıslah çalışmalarının yapılarak verimliliklerinin arttırılmasını ve sürdürülmesini, kullanımlarının sürekli olarak denetlenmesini, korunmasını ve gerektiğinde kullanım amacının değiştirilmesini $[20,21]$ içermektedir.

\section{3. Çalıșma Alanı}

Çalışma alanı Giresun ili bağlı Kümbet, Bektaş ve Çıkrıkkapı Yaylalarını içermektedir (Şekil 4). Kümbet Yaylası, Giresun ili Dereli ilçesi sınırlarında yer almaktadır. Dereli ilçesine 26 km, Giresun'a 62 km uzaklıktadır. Yayla, 1750-1950 m yükseklikleri arasına kurulmuş, aynı adı taşıyan Kümbet köyü 
(1400-1600 m) sınırları içerisinde bulunmakta olup, Uzundere köylüleri ile birlikte kullanılmaktadır. Yayla, köy statüsünde olduğundan hazine mülklerinin yanında özel mülkler de bulunmaktadır. Kümbet Turizm Merkezi, Kümbet yaylası yanısıra çevresindeki oba-yayla yerleşmelerini de içine alır. Bunlar arasında; Erenler yaylası, Can obası, Çeğerli yaylası, Tekke yaylası, Çomakkonağı obası, Yağmurca yaylası, Çeğerçukur obası, Köyyeri obası, Hamurlu obası ve Elemeği obası gibi çok sayıda oba-yayla yerleşmesi yer almaktadır (Şekil 1). Kümbet yaylası, yaylacılık sezonunda bu geçici yerleşmelerin merkezini oluşturur.

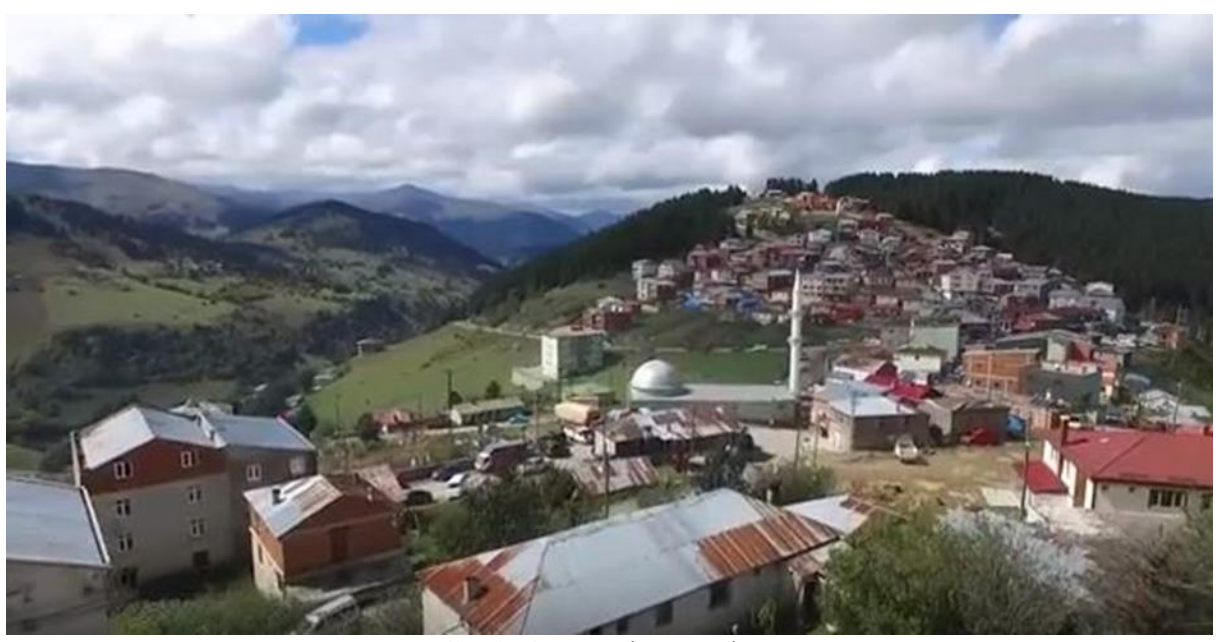

Şekil 1. Kümbet yaylası

Bektaş Turizm Merkezi, Giresun'a 56 km uzaklıkta olup merkezi 2000 - 2250 m yüksekliğe yayılmıştır. Merkez Kulakkaya Yaylası, Kurttepe Mevkii, Melikli Obası Yaylası ve Alçakbel Orman İçi Piknik Alanını içine alır (Şekil 2). Yaz başlarında bile kar görülen yaylada Kurttepe mevkiinde kışın kar kayağı, yazın çim kayağı yapılabilmektedir.

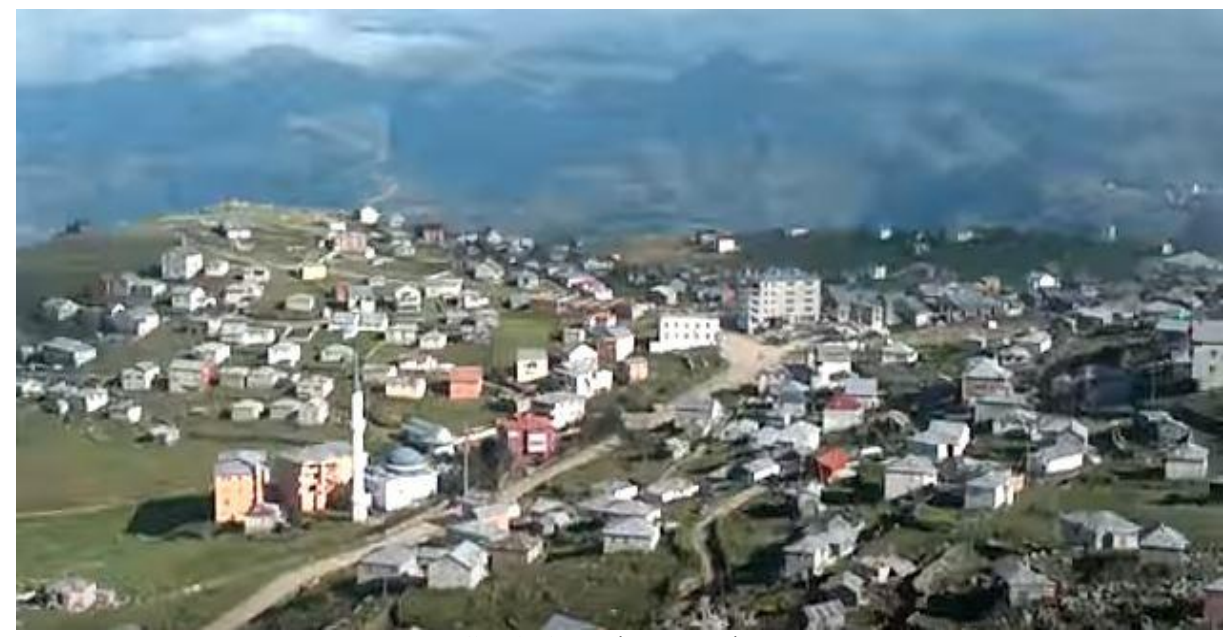

Şekil 2. Bektaş yaylası

Çıkrıkkapı Yaylası, Yağlıdere ve Alucra ilçe yaylalarını kapsamaktadır. Yaylada 1610 yılında inşa edildiği tahmin edilen Hacı Abdullah Duvarı, mevcuttur. 1 metre yüksekliğinde ve 6,5 kilometre uzunluğundaki duvar, Çıkrıkkapı Yaylası'na geçişi sağlamaktadır. Çin seddini andıran yapı mera alanları ile yerleşim alanlarını birbirinden ayıran bir çember şeklindedir (Şekil 3). 


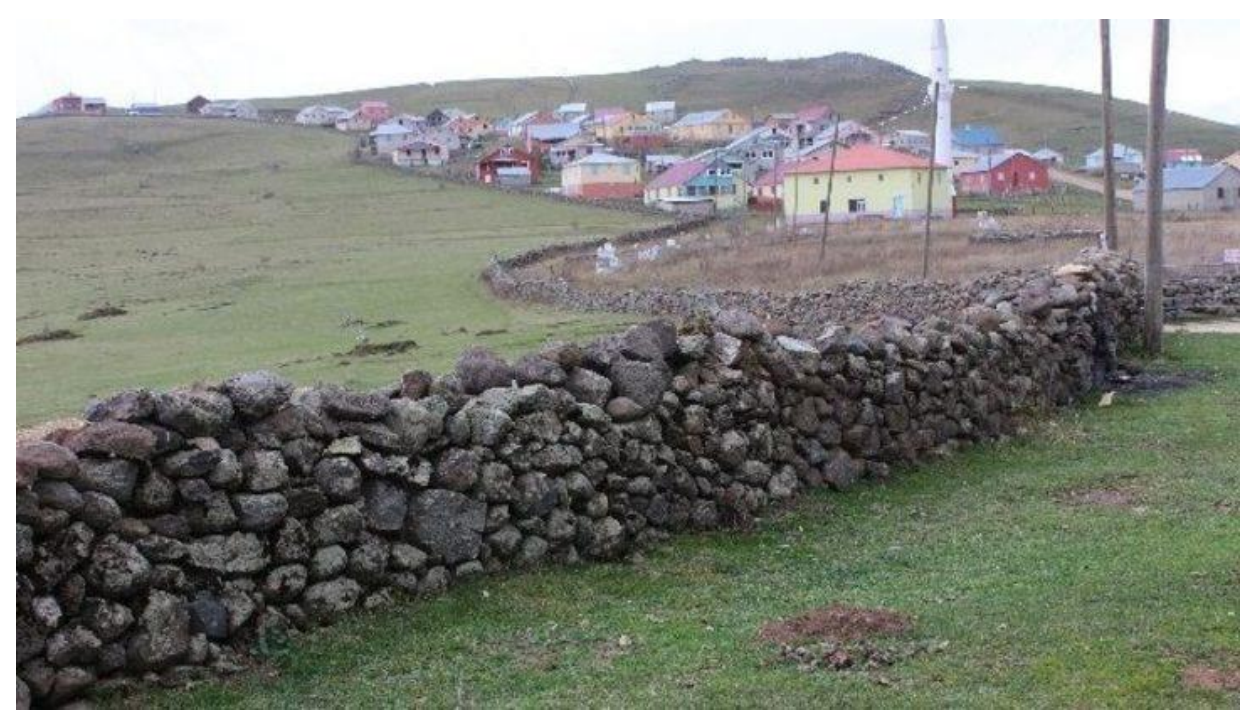

Şekil 3. Çıkrıkkapı Yaylası ve Hacı Abdullah Duvarı

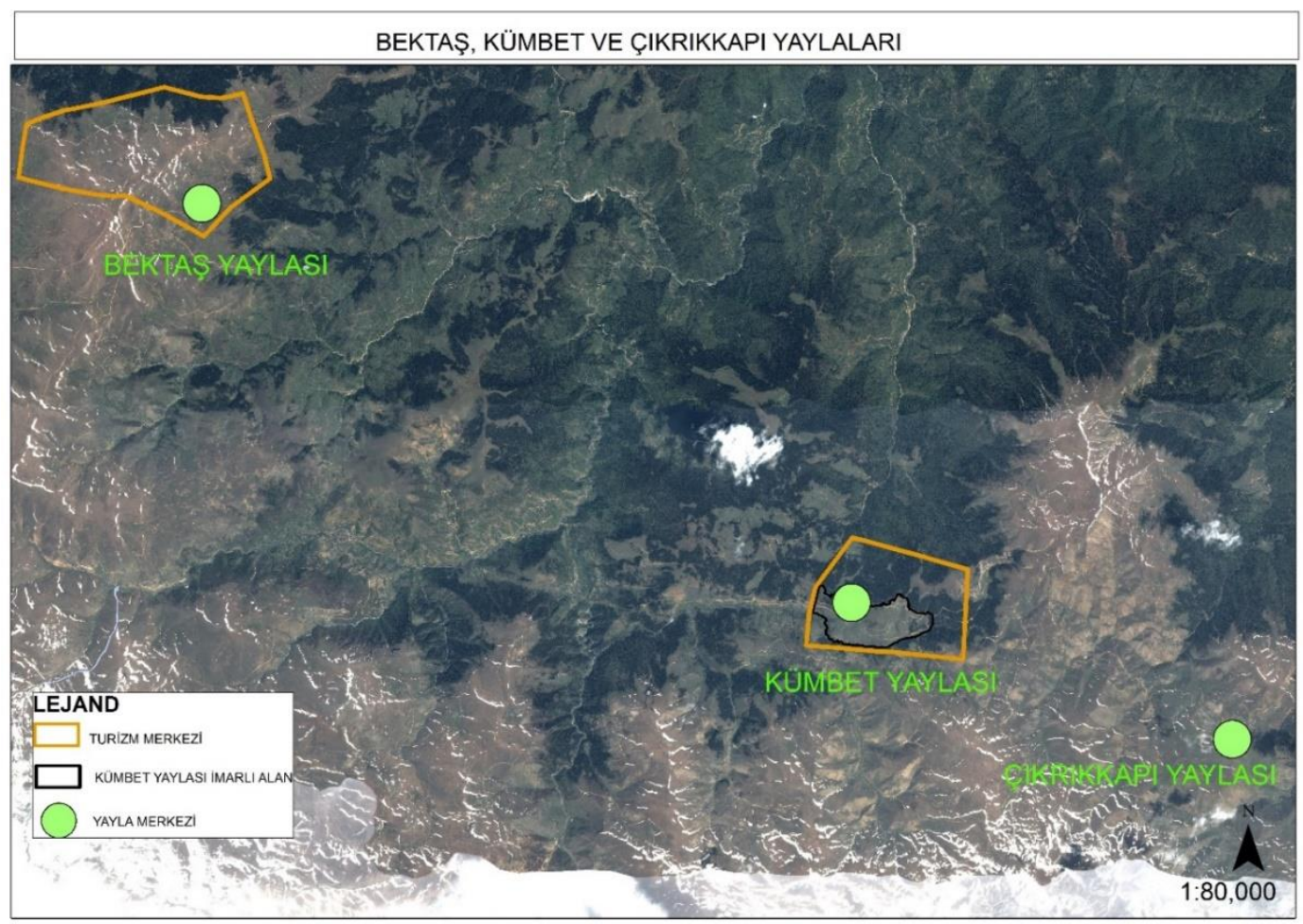

Şekil 4. Kümbet, Bektaş ve Çıkrıkkapı Yaylaları

\section{Materyal ve Yöntem}

Araştırmada nicel ve nitel araştırma teknikleri kullanılmıştır. Arazi kullanımında meydana gelen değişimi belirlemek amacıyla 1970, 2008 ve 2018 yıllarına ait 1:25.000 ölçekli hava fotoğraflarından yararlanılmıştır. Hava fotoğraflarının ortorektifikasyon işlemleri, 1:25.000 ölçekli yükseklik verileri, kamera kalibrasyon değerleri ve 1:25.000 ölçekli raster topoğrafik paftalar kullanılarak gerçekleştirilmiştir. Hava fotoğrafları, ArcGIS yazılımı kullanılarak arazi kullanımı verilerinin CBS verisi olarak üretilmesi sağlanmıştır. Bu kapsamda, 1970, 2008 ve 2018 yılları için Kümbet ve Bektaş ve Çıkrıkkapı yaylalarındaki binalar, merkez yerleşim alanı ile yollar üretilmiştir (Şekil 7, Şekil 8, Şekil 9). 


\section{Bulgular}

Giresun yaylalarının arazi kullanımında (1970-2008-2018 yılları arasında) meydana gelen değişimi belirlemek için yapılan analizlerde: Yaylalar da 1970 yılında evler genellikle tastan yapılmış olup, hayvanc1lık faaliyetlerine uygun fonksiyonel özelliklere sahip olarak inşa edilmiştir (Şekil 5).

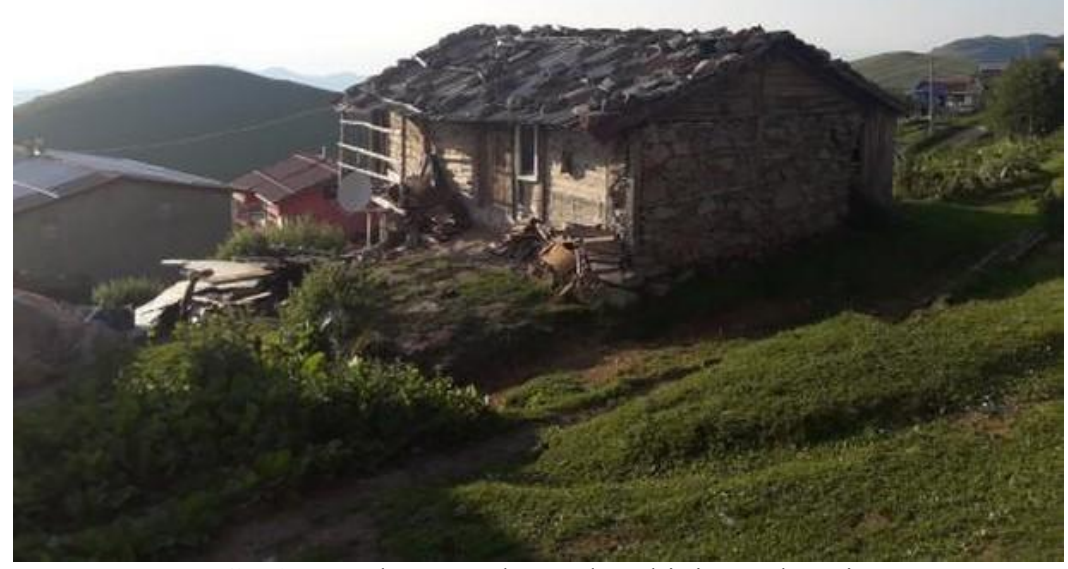

Şekil 5. Bektaş Yaylası'nda eski tip yayla evi

1970 yılında yaylalarda bir evin kapladığı alan yaklaşık olarak 60-70 m² dir. Aynı yılda yayla merkezleri yerleşim alanları Kümbet Yaylası'nda 5,41 ha, Bektaş Yaylası'nda, 34,96 ha, 'dır. Bu oranlar sırası ile 2008 yılında kümbet yaylasında, 15,73 ha, Bektaş yaylasında, 50,73 ha ve çıkrıkkapı yaylasında 22,93 ha'a ulaşmaktadır (Tablo 2). Merkezi yerleşim alanları hava fotoğrafları üzerinden o yılki mevcut yapılaşma yoğunluklarına göre çizilmiştir. Veriler ArcGIS'de sayısallaştırılmış, merkezi yerleşim alanı ve yollar vektörel veri katmanları üzerinden uzunluk ve alan hesaplamaları yapılmıştır.

Tablo 2. Kümbet, Bektaş ve Çıkrıkkapı yaylalarında arazi kullanım değişimi (1970-2008-2018)

\begin{tabular}{cccc}
\hline Yaylalar & Zamansal Değişim & Merkez Yerleşim Alanı (ha) & Yol (km) \\
\hline \multirow{3}{*}{ Kümbet Yaylası } & 1970 & 5,41 & 10,69 \\
& 2008 & 15,73 & 19,63 \\
\multirow{3}{*}{ Bektaş Yaylası } & 2018 & 25,50 & 20,86 \\
& 1970 & 34,96 & 11,07 \\
& 2008 & 50,73 & 17,68 \\
Çıkrıkkapı Yaylası & 2018 & 63,81 & 20,85 \\
& 1970 & - & - \\
& 2008 & 22,93 & 16,35 \\
& 2018 & 35,29 & 19,47 \\
\hline
\end{tabular}

2018 yılında merkezi yerleşim alanı 1970 yılına göre Kümbet Yaylası'nda \% 471 oranında, Bektaş Yaylası'nda merkezi yerleşim alanı \% 183 oranında artış göstermiştir. 2018 yılına ait analizlere ve arazi gözlemlerine göre evlerin niteliğinde büyük bir değişim olmuştur. Eski yayla evlerinde yap1 malzemesi olarak duvarlarda tas, çatı örtüsünde ise ahşap malzeme ve çinko ya da sacdan oluşan çatı örtüsü kullanılmışken, yeni yapılan evler betondan inşa edilmekle birlikte çok katlı gözlemlenmektedir. $\mathrm{Bu}$ evler yapım tarzı ve işlevleri bakımından geleneksel yayla evlerinin özelliklerini yansıtmamaktadır (Şekil 6). 


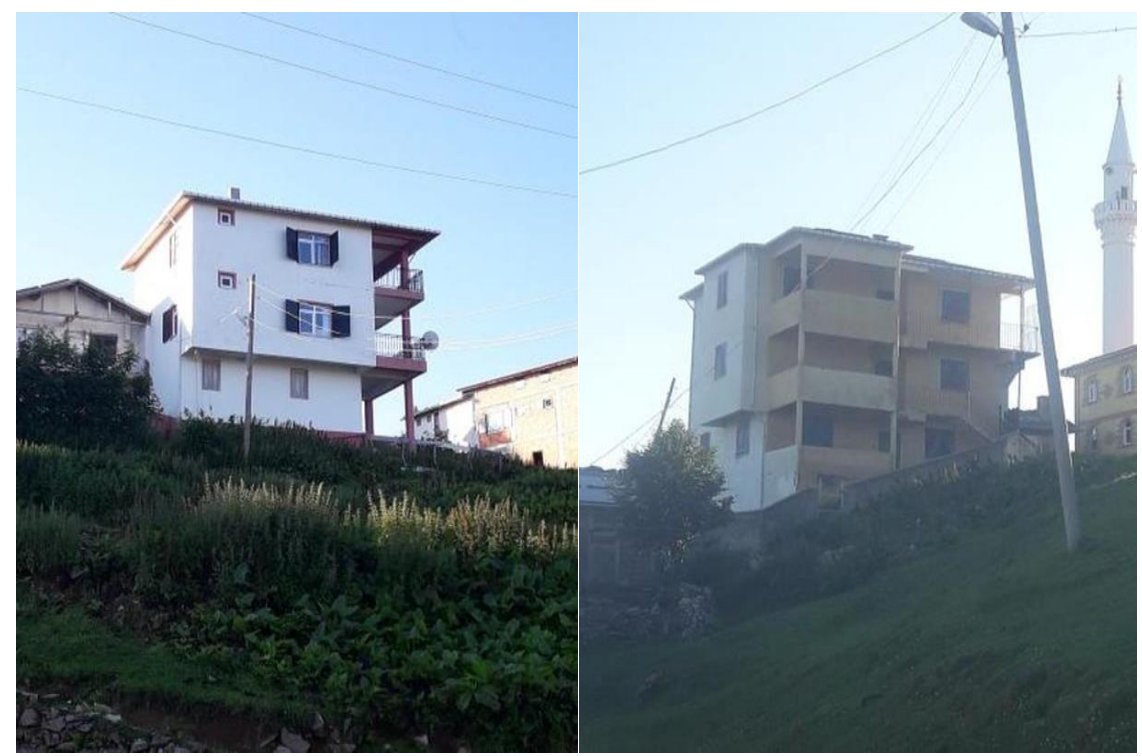

Şekil 6. Kümbet Yaylası'nda çok katlı evler

2018 yılı hava fotoğraflarının analizi ve arazi gözlemlerine göre son yıllarda yapılan evlerin büyüklüğü de geçmişe göre farklı olup, ortalama ev büyüklüğü 90-100 $\mathrm{m}^{2}$ olarak hesaplanmıştır. Buna göre 1970-2018 yılları arasında Kümbet, Bektaş ve Çıkrıkkapı yaylalarında ev yapımına bağlı olarak kayılplar meydana gelmiştir (Şekil 7, Şekil 8, Şekil 9).
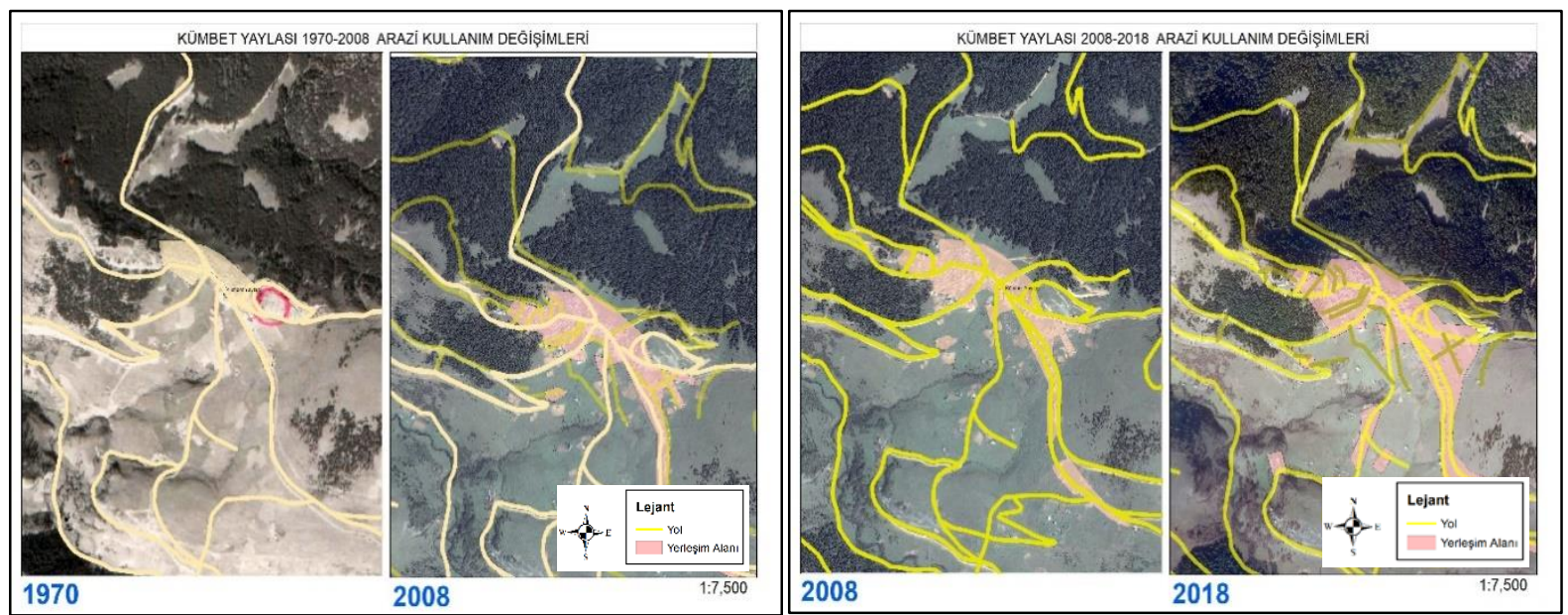

Şekil 7. Kümbet yaylası arazi kullanım değişimi 1970-2008 ve 2008-2018.
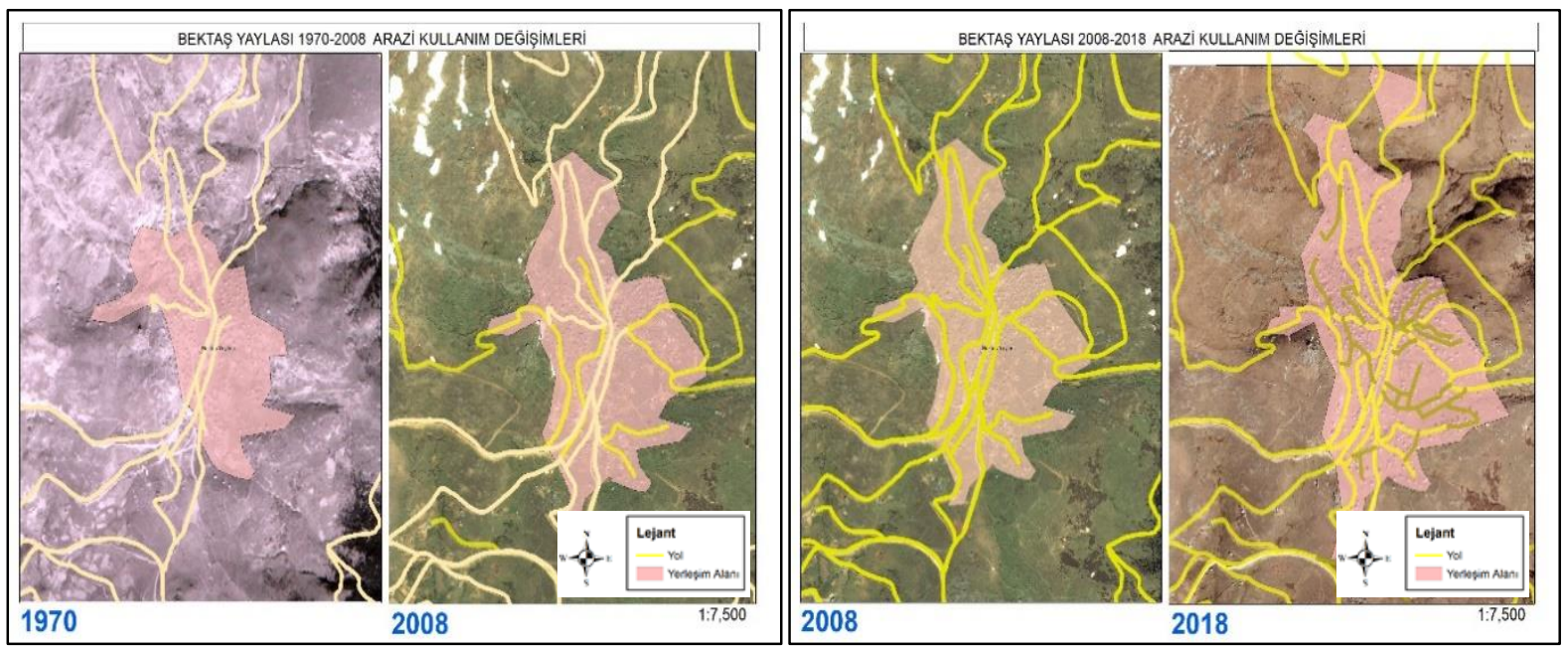

Şekil 8. Bektaş yaylası arazi kullanım değişimi 1970-2008 ve 2008-2018 


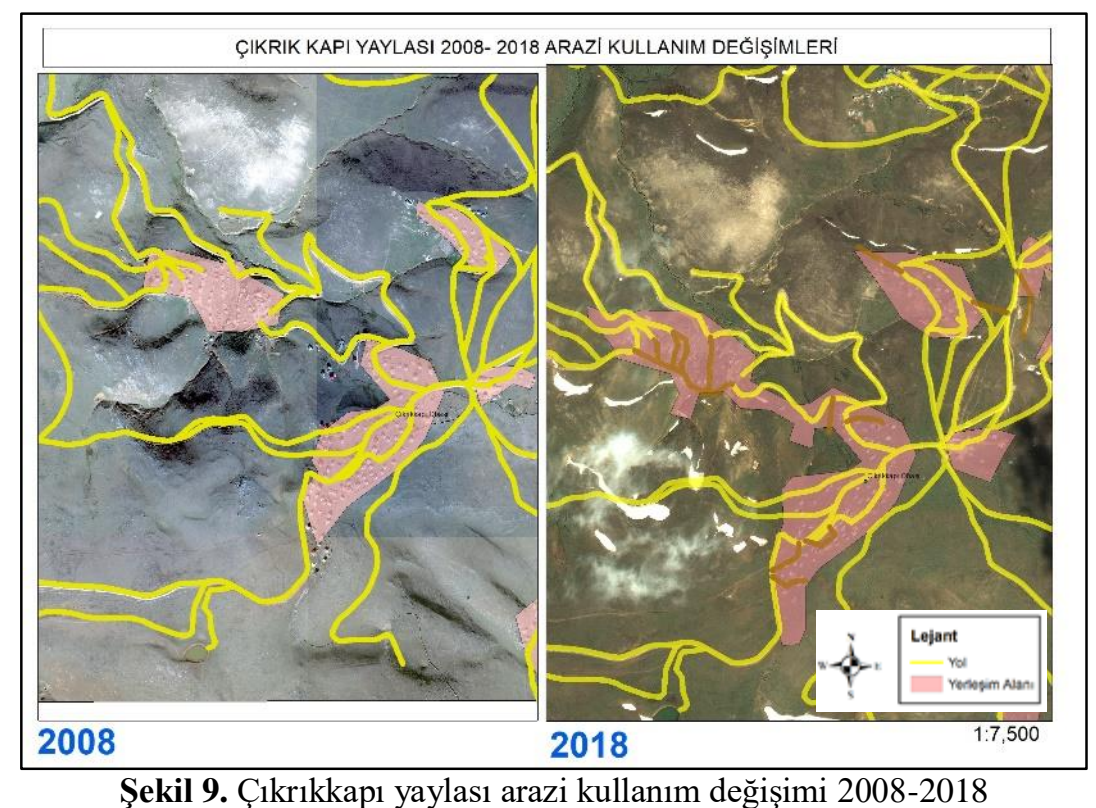

1970 yılında Kümbet Yaylası'nda 10,69 km, Bektaş Yaylası'nda 11,07 km yol ağı tespit edilmiştir. Bu yolların bir bölümü araba yolu bir bölümü de patika yoldur. 2018 yılında üç yaylada da yol ağında artış belirlenmiştir. Buna göre Kümbet Yaylası'ndaki yol ağı 20,86 km’ye, Bektaş Yaylası'ndaki yol ağı da 20,85 km'ye, Çıkrıkkapı yaylası ise 19,47 km'ye çıkmıştır (Tablo 2). Yol ağındaki artışın temel nedenleri, yeni yapılan evlere erişimin sağlanması, çevredeki diğer yaylalarla ulaşım bağlantısının sağlanmasıdır (Şekil 7, Şekil 8, Şekil 9).

\section{Sonuç ve Tartışma}

1970-2008-2018 yılları arasında arazi kullanımında meydana gelen değişimi belirlemek amacıyla yapılan analizler sonucunda; Kümbet Yaylası'nda 1970 yılında yayla merkez kullanım alanı 5,41 ha'dan \% 471 oranında artarak 2008 yılında 15,73 ha'a, 2018 yılında ise 25,50 ha ulaştığı; Bektaş Yaylası'nda 1970 yılında 34,96 ha'dan \% 183 oranında artarak 2008 y1lında 50,73 ha'a, 2018 yılında ise 63,81 ha'a ulaştığı tespit edilmiştir. Benzer şekilde Somoncu vd. 2010, yapmış oldukları çalışmada Gümüşhane ili Kazıkbeli ve Alistire yaylalarının arazi kullanımında 1973-2004 yılları arasında meydana gelen değişimi Kazıkbeli yaylasında \%400, Alistire yaylasında \%227 oranında arttığını belirlemişlerdir. Ayrıca çalışmada Mera Kanunu'nun kapsamı ve yaylaların kullanım biçiminin yeniden değerlendirilmesinde yarar bulunacağına vurgular yapılmıştır.

Yaylalar da eski tip yayla evleri, bölgenin geleneksel kırsal mimari özelliklerini yansıtan, tek katlı, basit planlı ve doğal malzemeden yapılmış tescil edilmemiş konutlardır. Yeni yapılan evler ise eskisinden farklı olarak betondan inşa edilmiş ve bazıları çok katlıdır. Yaylalardaki arazi kullanımında meydana gelen değişimin bir başka boyutu ise yaylalardaki yol ağında meydana gelen değişimdir. 19702018 yılları arasında Kümbet Yaylası'nda yol ağ 20,86 km, Bektaş Yaylası'nda 20,85 km, Çıkrıkkapı yaylasında ise 19,47 km'ye ulaşmıştır. Konut yapımı ve yol ağının geliştirilmesine bağlı olarak yaylaların kullanım alanlarında kayıplar ortaya çıkmış olup dağ ekosistemi bu durumdan zarar görmüştür. Bu durum mera alanlarında azalmalara neden olmuştur. Ayrıca bölgede yabancı turist talebinin yoğun olması nedeniyle turizm yatırımları artmıştır. Bu süreç arazi kullanımında ve yayla işlevlerinde hızlı bir değişim yapmıştır. Değişime bağlı olarak hayvancılığa dayalı geleneksel yaylacılık gerilemiş̧tir. Bu gerileme ise bölgedeki büyükbaş ve küçükbaş hayvan sayısının azalmasına ve hayvansal üretimin düşmesine yol açmıştır.

Sonuç olarak, çalışma mer'a alanlarının kayıt altına alınması gerekliliğini bir kez daha ortaya koymaktadır. Mera Kanunu tam olarak uygulanmalı ve yaylalarda kanunda öngörülenin dışında yapılaşma ve diğer uygulamalara kesinlikle izin verilmemelidir. Bununla birlikte günümüzde rekreasyonel talepler artmıştır. Yaylalar bu amaçlar için kullanılabilmelidir. Bu nedenledir ki yayla alanlarına ilişkin oluşturulacak imar planları çözüm için önemli kriterlerden biri olacaktır. 


\section{Kaynaklar}

[1] Çepel N. 1996. Çevre Koruma ve Ekoloji Terimleri Sözlüğü, TEMA Vakfı Yayınları, İstanbul.

[2] European Environment Agency. 2010. Land use. https://www.eea.europa.eu/themes/landuse (Erişim Tarihi: 02.05.2018)

[3] Verburg P.H., Steeg J., Veldkamp A., Willemen L. 2009. From land cover change to land function dynamics: A major challenge to improve land characterization, Journal of Environmental Management, 90: 1327-1335.

[4] Petit C.C., Lambin E.F. 2002. Impact of data integration technique on historical landuse/land-cover change: Comparing historical maps with remote sensing data in the Belgian Ardennes. Landscape Ecology, 17: 117-132.

[5] Ramankutty N., Foley J.A. 1999. Estimating historical changes in global land cover: croplands from 1700 to 1992. Global Biogeochemical Cycles, 13 (4): 997-1027.

[6] Kindu M., Schneider T., Döllerer M., Teketay D., Knoke T. 2018. Scenario modelling of land use/land cover changes in Munessa-Shashemene landscape of the Ethiopian highlands. Science of The Total Environment, 622: 534-546.

[7] Minta M., Kibret K., Thorne P., Nigussie T., Nigatu L. 2018. Land use and land cover dynamics in Dendi-Jeldu hilly-mountainous areas in the central Ethiopian highlands. Geoderma, 314: 27-36.

[8] Kassawmar T., Eckert S., Hurni K., Zeleke G., Hurni H. 2018. Reducing landscape heterogeneity for improved land use and land cover (LULC) classification across the large and complex Ethiopian highlands. Geocarto international, 33 (1): 53-69.

[9] Tolessa T., Senbeta F., Kidane M. 2017. The impact of land use/land cover change on ecosystem services in the central highlands of Ethiopia. Ecosystem services, 23: 47-54.

[10] Li A., Lei G., Cao X., Zhao W., Deng W., Koirala H.L. 2017. Land Cover Change and Its Driving Forces in Nepal Since 1990. In Land Cover Change and Its Eco-environmental Responses in Nepal, pp. 41-65.

[11] Rai R., Zhang Y., Paudel B., Li S., Khanal N.R. 2017. A synthesis of studies on land use and land cover dynamics during 1930-2015 in Bangladesh. Sustainability, 9 (10): 1866.

[12] Duhamel C. 2012. Land use, Land cover, including their classification. Encylopedia of life support system.

[13] Alemayehu F., Taha N., Nyssen J., Girma A., Zenebe A., Behailu M., Deckers S., Poesen J. 2009. The impacts of watershed management on land use and land cover dynamics in Eastern Tigray (Ethiopia), Resources, Conservation and Recycling, 53: 192-198.

[14] Chemini C., Rizzoli A. 2003. Land use change and biodiversity conservation in the Alps, J. Mt. Ecol., 7: 1-7.

[15] Coelho C.O.A., Carvalho T.M.M., Ferreira A.J.D. 1999. Land-use changes in Portuguese mountain areas: past, present and future, Edited by Price, M., Global Change in Mountains, USA, 123-124.

[16] Başıbüyük A., Yazıcı H., Ertürk M. 2001. Eğriçimen Yaylasında (Koyulhisar-Sivas) Rekreatif Yaylacılık, Türk Coğrafya Dergisi, 36: 31-48.

[17] Somuncu M. 2007. Kırsal ve Kentsel Alanlardaki Sosyoekonomik Değisime Bağlı Olarak Türkiye Yaylalarının Fonksiyonlarındaki Farklılasma, ICANAS 38. Uluslararası Asya ve Kuzey Afrika Çalısmaları Kongresi, pp778, Ankara.

[18] Somuncu M. 2010. The Dilemma in Turkish highlands: preservation of natural and cultural heritage and tourism development - A case study of the Eastern Black Sea Region, Proceedings of the 2nd International Conference on Heritage and Sustainable Development, 1: 431-440.

[19] Yalçınalp E. 2005. Trabzon'da Bazı Turizm Merkezleri Ölçeğinde Yayla Turizminin Ekoturizm Kapsamında İncelenmesi, KTÜ Fen Bilimleri Enstitüsü, Yüksek Lisans Tezi, Trabzon

[20] Aldağ E. 2011. Mer'a Kanunu ve Uygulanması, Balıkesir.

[21] Resmi Gazete, 1998. 4342 Say1l Mer'a Kanunu, http://www.resmigazete.gov.tr/arsiv/23272.pdf (Erişim Tarihi: 02.05.2018). 